\title{
Influence of saline soils and mineral fertilizers on the germination and formation of sunflower seeds
}

\author{
Alla Belovolova ${ }^{1}$, Natal'ya Gromova $^{1 *}$, Alexander Esaulko ${ }^{1}$, Evgeniy Golosnoy ${ }^{1}$, and Ylia \\ Grechishkina $^{1}$ \\ ${ }^{1}$ Stavropol State Agrarian University, lane Zootechnical 12, Stavropol, 355017, Russia
}

\begin{abstract}
The research was carried out with the aid of vegetation experiments and on saline soils in production crops of the Stavropol territory farms (Andropovsky, Mineralovodsky and Kochubeyevsky districts). The goal of the research was to identify patterns of germination and formation of sunflower seeds, depending on the influence of saline soils and the use of mineral fertilizers. It was found that sunflower seeds germinate at fairly high concentrations of soil salts. In vegetation experiments, where saline soil containing $1.14 \%$ and $1.71 \%$ of chloridesulfate salts was used, the number of sprouted seeds was $96.0 \%$ and $89.3 \%$ of the unsalted background, respectively, 14 days after sowing. The salinization type has a various impact on seed germination. A greater reduction in their germination was observed during sulfate-chloride salinization. The predominance of sulfates in the salt composition up to $0.4 \%$ did not have a negative effect on seed germination, while the predominance of chlorides reduced their germination, starting from $0.2 \%$. If the difference between the two types of salinization at $0.4 \%$ was only $2 \%$, then at $1.4 \%$ it reached $18 \%$, which indicates an increase in the toxic effects of chlorides as their concentrations increase. In the process of growing plants, soil salts affect plants directly through the root system.
\end{abstract}

\section{Introduction}

Saline soils are widespread in various regions of the Russian Federation and contain salts that are harmful to cultivated crops, which cause a decrease in their growth and productivity. The main components of their salt composition are chlorides and sulfates. Their effect on the plant manifests itself from the earliest stages, i.e. seed swelling and germination. High salt concentrations in the field cause the death of a large percentage of seedlings, which leads to their thinning [1,2].

The determining factor that limits soil fertility and determines its ecological state is soil salinization [3,4]. In Russia, about $20 \%$ of agricultural land is allocated for saline soils [5].

The unfavorable water-physical properties of these soils make it difficult to carry out technological operations regarding the cultivation of crops in the optimal time, which is

\footnotetext{
*Corresponding author: nikolenko0812@mail.ru
} 
also one of the significant reasons for the decrease in their productivity $[6,7]$.

The main reason for the delay in seed germination on saline soil is the difficulty in accessing the water necessary for the swelling of hydrophilic compounds. Therefore, the authors believe that the osmotic pressure of the soil solution can be considered the main negative factor during this period. However, the salinity impact consists of the osmotic pressure of the soil solution and its physiological imbalance. The impact of these factors during heterotrophic nutrition leads to a decrease in the mobilization of reserve substances for seed germination [8].

Natural saline soils are poor in accessible forms of nutrients, which are one of the reasons for inhibiting the growth and development of plants, reducing yield and worsening its quality.

Modern scientific literature on the fertilization of sunflower in various soil and climatic regions of the country is quite multifarious. According to the total number of nutrients consumed by plants during vegetation, sunflower is a crop of high demands $[9,10]$.

The critical period of sunflower nutrition regarding phosphorus coincides with the first weeks after germination [11,12]. Optimum phosphorus nutrition during this period accelerates the growing of plants, they consume moisture more economically $[13,14]$.

Modern ideas about the consumption of nutrients are based on knowledge of the plant's requirements for mineral nutrition. Sunflower is highly demanding on the presence of available nutrient forms in the soil [15].

\section{Materials and methods}

Location, program, research methodology. The research was carried out with the aid of vegetation experiments and on saline soils in production crops of the Stavropol territory industrial farms (Andropovsky, Mineralovodsky and Kochubeyevsky districts).

\section{Results}

According to the research carried out with the aid of vegetation experiments, the sunflower is characterized by a sufficiently high content of mineral salts in the aerial parts in case of soil salinization $(18.8 \%)$. At the same time, sunflower plants were also distinguished by a higher content of sulfate ion $(1.73 \%)$.

Sunflower seeds germinate at fairly high concentrations of soil salts. According to vegetation experiments, where a solonchak soil with a content of $1.14 \%$ and $1.71 \%$ of chloride-sulfate salts was used, the number of germinated seeds 14 days after sowing was $96.0 \%$ and $89.3 \%$ of the non-saline background, respectively. The salinization type has a various effect on seed germination. A greater reduction in their germination was observed in case of sulfate-chloride salinization (Table 1).

Table 1. Germination of sunflower seeds depending on the degree and quality of salinity (vegetation experiment)

\begin{tabular}{|c|c|c|c|c|c|c|c|}
\hline Salinity & \multirow{2}{*}{ Control } & \multicolumn{7}{|c|}{ Salination, \% } \\
\cline { 3 - 8 } quality & 0.2 & 0.4 & 0.6 & 0.8 & 1.0 & 1.4 \\
\hline $\begin{array}{c}\text { Chloride- } \\
\text { sulphate }\end{array}$ & 96 & 96 & 96 & 96 & 89 & 82 & 76 \\
\hline $\begin{array}{c}\text { Sulfate- } \\
\text { chloride }\end{array}$ & 96 & 95 & 94 & 86 & 74 & 68 & 58 \\
\hline
\end{tabular}

The predominance of sulfates in the salt composition up to $0.4 \%$ did not adversely affect seed germination, while the predominance of chlorides reduced their germination, 
starting from $0.2 \%$. If the difference between the two types of salinization at $0.4 \%$ was only $2 \%$, then at $1.4 \%$ it reached $18 \%$, which indicates an increase in the toxic effect of chlorides as their concentrations increase.

For the soil with natural chloride-sulfate salinization, the application of phosphorus fertilizer to the soil has a positive effect on seed germination. According to the vegetation experiment in this case, the number of germinated seeds increased by $5-7 \%$ in 14 days after sowing.

The beneficial effect of phosphorus can be explained by the fact that phosphoric acid is involved in the conversion mechanism of fats into carbohydrates, which plays the role of osmotically active compounds. This leads to an increase in the suction power of seeds and their absorption of water from saline soil.

The linear growth of plants at the initial stages of sunflower vegetation did not differ much depending on the type of soil salt composition, and it decreased by $46.3-47.7 \%$ at $1.4 \%$ of salts.

The accumulation of the total biological mass by the aerial parts of plants was more affected by the negative effect of the predominance of chlorides. So, in case of $1.4 \%$ chloride-sulfate salinization, the dry weight of one plant was $32.1 \%$, and $27.3 \%$ of the control variant in case of sulfate-chloride salinity (Table 2).

Table 2. The growth of sunflower depending on various salination types (vegetative experience, 40day plants)

\begin{tabular}{|c|c|c|c|c|c|c|}
\hline \multirow{4}{*}{$\begin{array}{c}\text { Salination, } \\
\%\end{array}$} & \multicolumn{6}{|c|}{ Salination type } \\
\hline & \multicolumn{3}{|c|}{ Chloride-sulphate } & \multicolumn{3}{|c|}{ Sulphate-chloride } \\
\hline & \multirow{2}{*}{$\begin{array}{l}\text { height, } \\
\mathrm{cm}\end{array}$} & \multicolumn{2}{|c|}{ dry mass of 1 plant } & \multirow{2}{*}{$\begin{array}{c}\text { height, } \\
\mathrm{cm}\end{array}$} & \multicolumn{2}{|c|}{ dry mass of 1 plant } \\
\hline & & $\mathrm{g}$ & $\%$ & & $\mathrm{~g}$ & $\%$ \\
\hline Control & 19.0 & 2.49 & 100 & 19.0 & 2.49 & 100 \\
\hline 0.2 & 18.5 & 2.26 & 90.7 & 18.5 & 2.18 & 87.5 \\
\hline 0.4 & 17.0 & 1.92 & 77.1 & 14.5 & 1.86 & 74.7 \\
\hline 0.6 & 15.5 & 1.70 & 68.3 & 14.0 & 1.63 & 65.4 \\
\hline 0.8 & 14.5 & 1.52 & 61.0 & 13.4 & 1.05 & 42.2 \\
\hline 1.0 & 12.6 & 1.11 & 44.6 & 11.8 & 0.85 & 38.1 \\
\hline 1.4 & 9.0 & 0.80 & 32.1 & 8.8 & 0.68 & 27.3 \\
\hline
\end{tabular}

The reduction in the mass of the aerial plant parts in case of sulfate-chloride salinization occurred mostly due to leaf area inhibition, and it showed a tendency to increase with increasing salinity.

The predominant inhibition of leaf growth is evidenced by a regular decrease in the leaf-stem ratio with increasing concentrations of both salination types. However, it is more prominent against the background of the predominance of chlorides.

The salination effect on the sunflower growth varies during the growing season. In the first 14 days after the emergence of seedlings, the daily gain of linear growth of fresh background plants was $0.56 \mathrm{~cm}, 0.26 \mathrm{~cm}$ on saline soil.

By the flowering phase, they were $1.28 \mathrm{~cm}$ and $1.37 \mathrm{~cm}$, respectively, which indicates a greater sensitivity of sunflower to salination in the first half of the growing season and its adaptation to this factor with increasing age.

The accumulation of dry mass by a whole sunflower plant exposed to salination decreased by almost half and increased significantly with the introduction of phosphorus fertilizer both separately and with nitrogen. In the phase of 3 leaf pairs, these options differed from the saline control by the excess of dry mass by $43.3-58.0 \%$. In the budding phase, they exceeded the control by more than two times, and by the flowering time, the greater advantage of nitrogen-phosphorus fertilizer remained (Table 3).

Against the background of the separate nitrogen fertilizer introduction in the phase of 3 - 
5 leaf pairs, inhibition of the biomass accumulation by plants was observed. However, its positive effect was observed in the budding and flowering phases. Along with the growth inhibition processes on saline soil, the development rates of sunflower also change. Here, the onset of developmental phases is accelerated by 2-3 days. The impact of nitrogen and phosphorus on the development of plants did not differ depending on the impact nature on this process in the conditions of zonal soil. Phosphorus nutrition accelerates the onset of development phases, and nitrogen leads to a delay in the onset and passage of phases throughout the vegetation period.

Table 3. The accumulation of dry mass by sunflower plants on saline soil

\begin{tabular}{|c|c|c|c|}
\hline \multirow{2}{*}{ Option } & \multicolumn{3}{|c|}{ Growth phase } \\
\cline { 2 - 4 } & $\begin{array}{c}\text { 3rd pair of } \\
\text { leaves }\end{array}$ & budding & flowering \\
\hline Control (non-saline soil) & 4.01 & 8.43 & 28.91 \\
\hline Control (saline soil without fertilizers) & 2.17 & 3.56 & 14.21 \\
\hline Saline soil + N & 1.90 & 3.92 & 17.54 \\
\hline Saline soil + P & 3.11 & 7.88 & 21.57 \\
\hline Saline soil + NP & 3.43 & 7.26 & 26.45 \\
\hline
\end{tabular}

Throughout the plant growth process, soil salts directly affect plants via the root system. The inhibition of the root system growth occurs due to the physical properties of saline soils, as well as the content of harmful salts in the root range.

The inhibitory effect of salts on the root system of sunflower starts from low concentrations. As the salinity level increases, the specific effect of salts gets most prominent. Thus, at $0.4 \%$ of salts, the root system of plants with a chloride-sulfate type of salinization exceeded that of a sulfate-chloride type by $1.5 \%$ in comparison with the nonsaline control, and by $11.7 \%$ at $1.4 \%$. On the contrary, the dry mass of the roots decreased with a concentration increase of salination types (Table 4), which was associated with less inhibition of lateral roots by chlorides.

Table 4. The development of the root system of sunflower depending on the quality and degree of soil salination (vegetation experiment, 30-day plants)

\begin{tabular}{|c|c|c|c|c|c|c|c|c|}
\hline \multicolumn{9}{|c|}{ Salination type } \\
\hline \multirow{2}{*}{$\begin{array}{c}\text { Salination } \\
\%\end{array}$} & \multicolumn{3}{|c|}{ Chloride-sulphate } & \multicolumn{3}{c|}{ Sulphate-chloride } \\
\cline { 2 - 9 } & \multicolumn{2}{|c|}{ length } & \multicolumn{2}{c|}{ mass } & \multicolumn{2}{c|}{ length } & \multicolumn{2}{c|}{ mass } \\
\cline { 2 - 9 } & $\mathrm{cm}$ & $\%$ & $\mathrm{~g}$ & $\%$ & $\mathrm{~cm}$ & $\%$ & $\mathrm{~g}$ & $\%$ \\
\hline Control & 48.0 & 100 & 0.43 & 100 & 48.0 & 100 & 0.43 & 100 \\
\hline 0.2 & 46.9 & 97.7 & 0.41 & 96.3 & 43.5 & 90.6 & 0.40 & 93.0 \\
\hline 0.4 & 41.3 & 86.0 & 0.40 & 93.0 & 40.6 & 84.5 & 0.33 & 76.7 \\
\hline 0.6 & 35.5 & 73.9 & 0.34 & 79.0 & 34.2 & 71.3 & 0.30 & 69.8 \\
\hline 0.8 & 34.4 & 68.3 & 0.29 & 60.4 & 33.8 & 70.4 & 0.23 & 53.5 \\
\hline 1.0 & 29.7 & 61.8 & 0.18 & 41.8 & 23.6 & 53.3 & 0.26 & 37.2 \\
\hline 1.4 & 24.4 & 50.8 & 0.12 & 27.6 & 18.8 & 39.1 & 0.11 & 25.5 \\
\hline
\end{tabular}

One of the factors stimulating the development and functional activity of the root system is the supply of plants with nutrients. The effect of both salinity and nutrients depends on the growth phase of sunflower. The length gain of the roots of plants growing in the phase of second leaf pair formation on saline soil were $15.1 \mathrm{~cm}$ behind plants growing on zonal soil (non-saline). This difference decreased by the flowering phase, which can be explained by an increase in salt and saline tolerance of plants in ontogenesis (Table 5).

In the first plant vegetation period, phosphorus fertilizer and its combination with nitrogen had a positive effect on the development of the root system. A greater advantage 
of nitrogen-phosphorus nutrition is observed in comparison with phosphorus nutrition, both in growth and in the formation of the total mass of the roots. This is associated with the intensive growth of lateral roots, which easily overcome the osmotic pressure of the soil solution.

Salinity of the soil inhibits the growth of above-ground organs the stronger, the higher its concentration. The reduction in plant growth against the background of sulfate-chloride salinity is more prominent in comparison with the predominance of sulfates.

Table 5. The effect of fertilizers on the growth of the root system of sunflower on saline soil (vegetation experiment, per 1 plant).

\begin{tabular}{|c|c|c|c|c|c|c|}
\hline \multirow{3}{*}{ Option } & \multicolumn{3}{|c|}{ Length, $\mathrm{cm}$} & \multicolumn{3}{|c|}{ Mass, $\mathrm{g}$} \\
\hline & \multicolumn{6}{|c|}{ Growth phase } \\
\hline & $\begin{array}{l}\text { 2nd pair } \\
\text { of leaves }\end{array}$ & budding & flowering & $\begin{array}{l}\text { 2nd pair } \\
\text { of leaves }\end{array}$ & budding & flowering \\
\hline $\begin{array}{l}\text { Control (non- } \\
\text { saline soil) }\end{array}$ & 40.5 & 54.2 & 63.2 & 1.29 & 2.49 & 5.28 \\
\hline $\begin{array}{c}\text { Control (saline } \\
\text { soil without } \\
\text { fertilizers) }\end{array}$ & 25.4 & 40.7 & 52.1 & 0.47 & 0.52 & 2.18 \\
\hline Saline soil + N & 23.0 & 41.8 & 53.0 & 0.38 & 0.69 & 2.33 \\
\hline Saline soil + P & 37.0 & 50.1 & 59.0 & 0.89 & 2.00 & 3.47 \\
\hline Saline soil + NP & 29.6 & 48.4 & 61.2 & 0.84 & 2.16 & 4.00 \\
\hline
\end{tabular}

As a result, the positive role of the optimization factor for the mineral nutrition of plants was revealed by applying fertilizers to saline soil, in order to increase resistance to salinity and improve its quality. At the same time, changes in the use of nutrients from the soil are first considered in connection with the level of their salt tolerance.

\section{Conclusion}

An increase in soil salinity is accompanied by an increase in its destructive effect on the growth of aboveground sunflower organs. The negative impact of sulfate-chloride salination is more prominent. The positive effect of phosphorus and nitrogen on growth processes when they are introduced into saline soil differs throughout the ontogenesis of sunflower.

\section{References}

1. A.A. Belovolova, O.Yu Lobankova, , N.V. Gromova, , A.Yu Ozheredorova, , S.A. Korostylev. IOP Conference Series: Earth and Environmental Sci., 315(7), 072013 (2019). doi: 10.1088/1755-1315/315/7/072013

2. Y.I. Grechishkina, E.V. Golosnoy, A.N. Esaulko, M.S. Sigida, A.Y. Ozheredova. IOP Conference Series: Earth and Environmental Sci., 315(5), 052030 (2019). doi:10.1088/1755-1315/315/5/052030.

3. E. Ebrahimian, S. Mohammad Seyyedi, A. Bybordi, C.A. Damalas. Agricultural Water Management, 218, 149-157 (2019). doi.:10.1016/j.agwat.2019.03.031

4. M. Hussain, S. Farooq, W. Hasan, S. Ul-Allah, A. Nawaz. Agricultural Water Management, 20131, 152-166 (2018). doi.:10.1016/j.agwat.2018.01.028.

5. K. Mohammadi, G. Heidari, M. Javaheri, A. Rokhzadi,R. Talebi, Industrial Crops and Products, 44, 446-451 (2013). doi.:10.1016/j.indcrop.2012.09.028. 
6. C. Alberio, N. G. Izquierdo, L. A. N. Aguirrezábal, Sunflower, 53-91 (2015). doi.: 10.1016/B978-1-893997-94-3.50009-X.

7. B. T. Steer, P. D. Coaldrake, C. J. Pearson, C. P. Canty. Field Crops Research. 13, 99115 (1986). doi.:10.1016/0378-4290(86)90014-6.

8. Y.I. Grechishkina, , E.V. Golosnoy, F.N. Esaulko, M.S. Sigida,A.Y. Ozheredova, IOP Conference Series: Earth and Environmental Science 315(5), 052030 (2019). doi.: 10.1088/1755-1315/315/5/052030//

9. A.N. Esaulko, Y.I. Grechishkina, M.S. Sigida, S.A. Korostilev, E.V. Golosnoi, Oriental Journal of Chemistry, 32 (6), 3189-3199. (2016). doi: 10.13005/ojc/320642.

10. A. Esaulko, M. Sigida, E. Golosnoy, S. Antonov, O. Lobankova, Engineering for Rural Development 18, 391-396 (2019). doi.:10.22616 / ERDev2019. 18.N204.

11. D. Spinelli, L. Bardi, A. Fierro, S. Jez, R. Basosi. Journal of Environmental Management. 129, 302-308 (2013). doi.:/10.1016/j.jenvman.2013.07.029.

12. S. Li, Y. Duan et al., Journal of Integrative Agriculture. 17(12), 2802-2812 (2018). doi.: org/10.1016/S2095-3119(18)62074-X.

13. S. Zamani, M.R. Naderi, A. Soleymani, B.M. Nasiri. Ecotoxicology and Environmental Safety. 190, 110017 (2020). doi.:/10.1016/j.ecoenv.2019.110017.

14. M. Kiani, M. Gheysari, B. Mostafazadeh-Fard, M. Mahdi Majidi, G. Hoogenboom. $\begin{array}{lllll}\text { Agricultural Water Management. 171, 162-172 (2016). doi.: } & \end{array}$ /10.1016/j.agwat.2016.04.008.

15. P. S. Minhas, T. B. Ramos, A. Ben-Gal, L. S. Pereira. Agricultural Water Management. 227, 105832 (2020). doi.:/10.1016/j.agwat.2019.105832. 